\title{
Free radical reaction products and antioxidant capacity in arterial plasma during coronary artery bypass grafting
}

Oxygen free radicals mediate the ischemia-reperfusion damage in animal hearts, but their role in human beings is still controversial because of the low xanthine oxidase level in the human heart. Besides ischemia-reperfusion, cardiac operation also includes other major interventions that might generate free radicals but have not been systematically studied. We studied the cases of nine patients throughout coronary artery operations, including general anesthesia, heparin, protamine and administration of cardioplegic solution, extracorporeal circulation, and heart reperfusion. Arterial plasma was assayed for malondialdehyde, diene conjugates, and fluorescent chromolipids, and plasma antioxidant activity was estimated from the ability to trap peroxyl radicals. Anesthesia, surgical procedures, or heparin administration did not change these parameters. Extracorporeal circulation decreased the plasma concentration of diene conjugates immediately, whereas other compounds remained unaltered. When these concentrations were corrected for hemodilution, the amount of fluorescent chromolipids actually increased after 5 minutes of extracorporeal circulation to $177 \% \pm 14 \%$ (mean \pm standard error of the mean), diene conjugates increased to $138 \% \pm 12 \%$, and plasma antioxidant capacity increased to $144 \% \pm 12 \%$ of the awake value. Fluorescent chromolipid values remained at $156 \%$ to $177 \%$ throughout the perfusion and decreased to $130 \% \pm 13 \% 1$ hour after perfusion. Diene conjugate levels and antioxidant capacity were $123 \%$ to $144 \%$ and $143 \%$ to $161 \%$, respectively, from baseline during perfusion and $119 \% \pm 5 \%$ and $135 \% \pm 9 \%$, respectively, 1 hour after perfusion. Heart reperfusion or protamine administration showed no additional increases. Malondialdehyde concentrations varied and showed no statistically significant alterations. We conclude that extracorporeal circulation devices induce generation of free radicals and plasma antioxidant activity, which are different from the damage caused by ischemia-reperfusion. (J THORAC CardiovasC Surg 1994; 108:140-7)

Hannu J. Toivonen, $\mathrm{MD}, \mathrm{PhD},{ }^{\mathrm{a}}$ and Markku Ahotupa, $\mathrm{PhD},{ }^{\mathrm{b}}$ Helsinki and Turku, Finland

xygen free radicals damage cells by, for example, breaking DNA and protein strands and by destroying cell

From the Department of Anesthesia, Helsinki University Central Hospital, Helsinki ${ }^{\mathrm{a}}$; and the MCA Research Laboratory, Department of Physiology, University of Turku, Turku, ${ }^{b}$ Finland.

Supported by the Academy of Finland and the Juho Vainio Foundation, Helsinki, Finland.

Received for publication Aug. 25, 1993.

Accepted for publication Jan. 3, 1994.

Address for reprints: Hannu J. Toivonen, MD, Department of Anaesthesia, Helsinki University Central Hospital, Haartmaninkatu 4, SF-00290, Helsinki, Finland.

Copyright $\odot 1994$ by Mosby-Year Book, Inc.

$0022-5223 / 94 \$ 3.00+0 \quad \mathbf{1 2 / 1 / 5 4 0 7 6}$ membranes by means of lipid peroxidation., ${ }^{1,2}$ They are, however, not only detrimental but also an essential part of normal respiratory function inside mitochondria; for example, phagocytic cells produce them to destroy foreign material.

Cellular ischemia followed by reperfusion is one of the situations in which free radical production may overwhelm the capacity of natural antioxidants. Clinically, ischemia-reperfusion is present during cardiac operation when the aorta is first crossclamped and the heart is then reperfused with highly oxygenated blood. Simultaneously, extracorporeal circulation exposes blood to foreign surfaces that activate leukocyte defense mechanisms. Cardiac ischemia-reperfusion damage by free radicals is 
well documented in several animal species, but it has not yet been systematically studied in human beings. Clinical studies have shown, however, that thiobarbituric acid (TBA) reactive material (malondialdehyde), ${ }^{3-6}$ diene conjugates, ${ }^{4,7-8}$ oxidized glutathione, ${ }^{9}$ hydrogen peroxide $^{10-11}$ or chemiluminescence products from neutrophils $^{6,12}$ or from cardiac muscle ${ }^{13}$ are formed during cardiac operation, and this increase usually occurs at the time of heart reperfusion. The use of allopurinol, an inhibitor of xanthine oxidase, has also produced some clinical improvement during cardiac operations, ${ }^{14-15}$ although the activity of xanthine oxidase in human heart tissue has been reported to be low or nonexistent. ${ }^{2,16}$

Cardiac operations contain several major homeostatic interventions in addition to the ischemia and reperfusion. These include general anesthesia, administration of heparin and protamine in high doses, extracorporeal circulation, hemodilution, and cardioplegia. Formation of shortlived free radicals cannot be measured directly in intact tissues, but it can be estimated from the formation of stable peroxidation products. We have now studied the appearance of three different peroxidation end products, that is, fluorescent chromolipids, TBA reactive material (malondialdehyde), and diene conjugates throughout these major intervention points in nine patients undergoing coronary artery bypass grafting (CABG). Whenever possible the patients were not given drugs with antioxidant properties. We simultaneously measured the plasma antioxidant capacity, which to our knowledge, has not been previously reported for patients who undergo cardiac operation.

\section{Patients and methods}

We studied the cases of nine randomly selected patients $(7$ male, 2 female) scheduled for elective CABG procedures because of double or triple vessel coronary artery disease. Four of the patients had had myocardial infarction previously, but none of them had signs of acute myocardial infarction. The study was approved by the local medical ethics committee, and the patients gave informed consent. The mean age was 63 years (range, 55 to 72 years). They received two to five grafts, including one from the left internal thoracic artery, one from the right internal thoracic artery in two cases, and saphenous vein grafts. The aortic crossclamp time was 49 minutes (median; range, 23 to 92 minutes) and the extracorporeal circulation lasted for 84 minutes (median; range, 49 to 161 minutes). All patients were receiving standard antianginal therapy, which included at least two components of the triplet $\beta$-adrenergic blocking agents, nitrates, or calcium channel blocking agents. The last dose was given 2 hours before arrival to the operation area. The premedication consisted of scopolamine $(4 \mu \mathrm{g} / \mathrm{kg})$ and morphine (130 $\mu \mathrm{g} / \mathrm{kg}$ ), given intramuscularly 1 hour before arrival to the operation area. Patients receiving other medications with known antioxidant activity were excluded from the study.
Anesthesia, surgical procedure, and cardiopulmonary bypass. A radial artery cannula was placed, while the patient was awake, for blood sample collection and hemodynamic monitoring. Anesthesia was induced with diazepam ( 2.5 to $5 \mathrm{mg}$ ), fentanyl $(30 \mu \mathrm{g} / \mathrm{kg})$, and pancuronium and supplemented with fentanyl and enflurane (isoflurane in one case) as required. The patients' lungs were ventilated with $100 \%$ oxygen throughout the operation, except during the extracorporeal circulation. After median sternotomy and internal mammary artery dissection, the patients were heparinized $(200 \mathrm{IU} / \mathrm{kg}$, then $100 \mathrm{IU} / \mathrm{kg}$ 5 minutes later), and a heparin dose response curve against activated clotting time was constructed. Additional heparin doses were given to keep activated clotting times over 480 seconds. After cardiopulmonary bypass (CPB), the remaining heparin was reversed with protamine sulfate given in a dose of $1.3 \mathrm{mg} / 100 \mathrm{IU}$ heparin, as estimated from the heparin dose/ activated clotting time response curve. The patients underwent perfusion during CPB with nonpulsatile flow from a hollow-fiber membrane oxygenator (Compactflo, Dideco, Mirandola, Italy; or Maxima, Medtronic, Anaheim, Calif.) which was flushed with $100 \%$ oxygen at a rate maintaining non-temperature-corrected alveolar carbon dioxide tension values at normal levels (alpha-stat principle). The circuit was primed with 2000 $\mathrm{ml}$ of Ringer's acetate (Ringersteril, Medipolar, Oulu, Finland), and the blood flow was adjusted to $2.4 \mathrm{~L} / \mathrm{min}$ per square meter and reduced to 1.5 to $1.8 \mathrm{~L} / \mathrm{min}$ per square meter during hypothermia (nasopharyngeal temperature $28^{\circ} \mathrm{C}$ ). The heart was protected initially with $1000 \mathrm{ml}$ of cold crystalloid cardioplegic solution (Plegisol; Abbott, North Chicago, Ill.) containing 120 $\mathrm{mEq}$ of sodium, $16 \mathrm{mEq}$ of potassium, $32 \mathrm{mEq}$ of magnesium, $2.4 \mathrm{mEq}$ of calcium, $160 \mathrm{mEq}$ of chloride, and $10 \mathrm{mEq}$ of bicarbonate; additional doses were given as required to maintain silence on the electrocardiogram during the aortic crossclamp period. Mannitol was not given, but adequate diuresis was maintained with furosemide if required. All blood vented from the left ventricle, and the bleeding from the thoracic cavity was continuously returned to the venous reservoir of the oxygenator to maintain circulating red cell mass as constant as possible. No banked blood was used during the operations.

Sampling protocol. Serial blood samples were drawn from the radial artery cannula for on-site blood gas and hematocrit level measurement and for free radical product analysis. The latter samples were drawn into vacuum tubes (Vacutainer; Terumo, Leuven, Belgium) containing dry Li-heparin. The tubes were placed immediately on ice, and the plasma was separated on a centrifuge $\left(4^{\circ} \mathrm{C}, 3000 \mathrm{~g}, 10\right.$ minutes $)$ during the first 30 minutes. The separated plasma was then immediately frozen to $-70^{\circ} \mathrm{C}$ until assayed. The samples were collected at 13 time points (Fig. 1).

Urine samples. The patients voided 2 hours before the arrival to the operation area. The urine volume in the bladder was measured, when the urinary catheter was inserted immediately after anesthesia induction and a $3 \mathrm{ml}$ sample of urine was frozen to $-70^{\circ} \mathrm{C}$ for fluorescent chromolipid assay. Urine volume excreted during each hour thereafter was measured, and a $3 \mathrm{ml}$ sample was always stored for analysis.

\section{Measurement of free radical products}

Fluorescent chromolipids. Fluorescent chromolipids were assayed from the plasma and urine samples essentially as described by Esterbauer and associates. ${ }^{17}$ The samples were eluted with chloroform-methanol $(2: 1)$ and centrifuged at a max- 


\section{CORRECTED FOR HEMODILUTION}

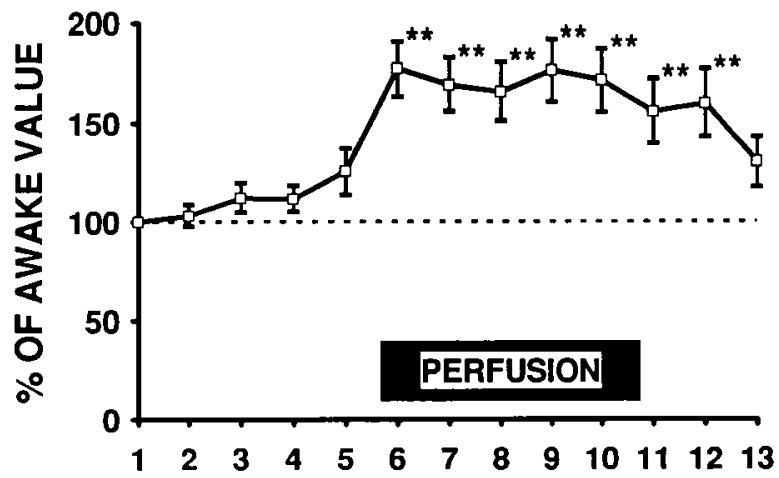

NOT CORRECTED FOR HEMODILUTION

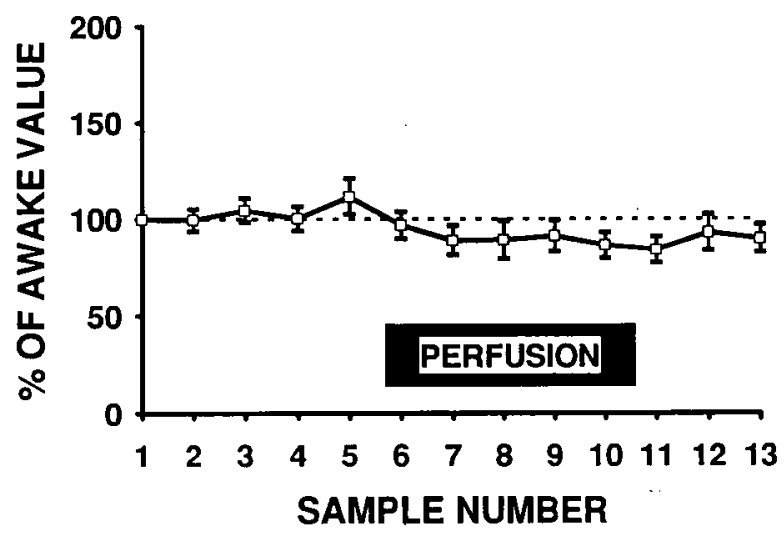

Fig. 1. Line graphs showing relative amount of fluorescent chromolipids in arterial plasma during different phases of CABG operation. Upper panel shows values after correction for hemodilution; lower panel shows actual measured plasma concentrations as percentage of first data point (mean \pm SEM of nine patients). Sample times: 1 : before anesthesia induction; 2 : 10 minutes after anesthesia induction; $3: 45$ minutes after anesthesia induction; 4: before heparin $(200 \mathrm{IU} / \mathrm{kg}) ; 5: 5$ minutes after heparin; $6: 5$ minutes from the start of extracorporeal circulation; $7: 5$ minutes after administration of cardioplegic solution; 8: 45 minutes from the start of extracorporeal circulation $(n=7)$; 9: before aortic crossclamp removal; 10:5 minutes after crossclamp removal; 11:5 minutes after the termination of CPB 12: after protamine administration; 13: 1 hour from the end of extracorporeal circulation. ${ }^{*}$ Two $\times p<0.01$, difference from the first sample by analysis of variance followed by the Newman-Keuls test.

imum of $2000 \mathrm{~g}$ for 10 minutes. The organic phase was evaporated to dryness and redissolved in chloroform-methanol $(10: 1)$, whereafter the fluorescence was measured at $360 \mathrm{~nm}$ (excitation) $/ 430 \mathrm{~nm}$ (emission). The coefficient of variation between assays in our laboratory has been $9.2 \%$.
Diene conjugates. Lipids were extracted from the plasma samples by chloroform-methanol (2:1), dried under nitrogen, then redissolved in cyclohexane, and analyzed spectrophotometrically at $232 \mathrm{~nm}$, as described by Corongiu, Lai, and Milia. ${ }^{18}$ The coefficient of variation between assays in our laboratory has been $6.3 \%$.

$T B A$ reactive material (malondialdehyde). Plasma samples were diluted in phosphate buffer and heated together with a TBA solution $(325 \mathrm{mg} / \mathrm{ml})$ in a boiling water bath for $15 \mathrm{~min}-$ utes. The tubes were then cooled and absorbances measured at $535 \mathrm{~nm} .{ }^{19}$ 1,1,3,3,-Tetraethoxypropane (Sigma Chemical Co., St. Louis, Mo.) was used as a standard. The coefficient of variation between assays in our laboratory has been $9.2 \%$.

Plasma antioxidant capacity. The ability of plasma to trap free peroxyl radicals generated from azobis (2-amidinopropane) hydrochloride was measured as described previously. ${ }^{20,21}$ In brief, antioxidants prevent the reaction of formed radicals with luminol and chemiluminescence is prevented as long as antioxidants are available.

Correction for plasma dilution. Red cells were used as a nondiffusible indicator. The concentrations measured in plasma were corrected for dilution by the following equation:

$$
\begin{aligned}
& \text { Corrected value }= \text { measured value } \times \mathrm{Hct}_{\mathrm{l}} \times\left(1-\mathrm{Hct}_{2}\right) / \\
& \mathrm{Hct}_{2} \times\left(1-\mathrm{Hct}_{1}\right)
\end{aligned}
$$

where $\mathrm{Hct}_{1}$ is initial hematocrit level in the first sample at preinduction and $\mathrm{Hct}_{2}$ is the sample hematocrit level. Total red cell mass was assumed to remain constant: all the bleeding was returned to the circuit, and no banked blood was used.

Statistical analysis. The plasma free radical reaction product concentrations versus time were compared with analysis of variance for repeated measures, followed by the Newman-Keuls test. Urinary excretion of fluorescent chromolipids was compared nonparametrically by Friedman's test and by the Wilcoxon signed-rank test. Two $\times p$ values less than 0.05 were regarded as significant.

\section{Results}

Fluorescent chromolipids. The absolute concentration of fluorescent chromolipids in plasma remained unchanged throughout the operation, with no effect of general anesthesia, heparin, extracorporeal circulation, reperfusion, or protamine administration (Fig. 1, lower panel). The introduction of extracorporeal circulation, however, created a significant hemodilution when $2 \mathrm{~L}$ of crystalloid prime and $1 \mathrm{~L}$ of cardioplegic solution were added in the circulation. When the results are corrected for this hemodilution (Fig. 1, upper panel), they show a significant increase in plasma fluorescent chromolipid content immediately when extracorporeal circulation was started and the increase remained at this level throughout the extracorporeal circulation period. The reperfusion after aortic crossclamp removal or the administration of protamine at the end of the extracorporeal circulation did not show any additional effect on the levels of fluorescent chromolipids. The last value, measured 1 hour after the cessation of extracorporeal circulation had returned toward the preoperative value and was not significantly 
Table I. Appearance of fuorescent chromolipids in urine during $C A B G$ operation

\begin{tabular}{|c|c|c|c|c|}
\hline \multirow{2}{*}{$\begin{array}{l}\text { Hours under } \\
\text { anesthesia }\end{array}$} & \multicolumn{2}{|c|}{$\begin{array}{l}\text { Urine volume } \\
\qquad(m l)\end{array}$} & \multicolumn{2}{|c|}{$\begin{array}{l}\text { Total amount } \\
\text { of fluorescent } \\
\text { chromolipids } \\
\text { (arbitrary units) }\end{array}$} \\
\hline & Median & Range & Median & Range \\
\hline 1 & 35 & $0-150$ & 1750 & $0-5550$ \\
\hline 2 & 28 & $0-530$ & 2529 & $0-15480$ \\
\hline 3 & $270^{*}$ & $0-1000$ & $10150^{*}$ & $330-26600$ \\
\hline 4 & $305^{*}$ & $60-500$ & $9215^{*}$ & $6670-86000$ \\
\hline
\end{tabular}

Total amount (concentration $\times$ urine volume) of fluorescent chromolipids in urine increased during operation. Extracorporeal circulation started during the second hour in seven cases and during the third hour in the remaining two cases.

${ }^{*}$ Two $\times p<0.05$, difference from the first hour sample by Friedman's test and by the Wilcoxon signed-rank test.

elevated. These lipids also appeared in urine (Table I). The concentration in urine did not change significantly, but the volume of urine excreted increased during the extracorporeal circulation, and the total amount of fluorescent material excreted via the kidneys increased accordingly. The patients voided about 2 hours before arrival to the operation area. The urine volume in the bladder was, 0 to $250 \mathrm{ml}$ (median, $40 \mathrm{ml}$ ), and the corresponding amount of fluorescent chromolipids was 0 to 12500 arbitrary units (median, 450). These values increased severalfold during the operation and, for example, during the fourth hour of the operation, 1-hour urine output was 60 to $500 \mathrm{ml}$ (median, $305 \mathrm{ml}$ ). The corresponding amount of fluorescent chromolipids was 6670 to 86000 units (median, 9215 units). Urine was collected in 1-hour aliquots because it was technically impossible to synchronize collected urinary aliquots with sudden circulatory changes. These results, however, show that measured plasma concentrations may underestimate the real rate of fluorescent chromolipid formation because of the continuous urinary excretion.

Diene conjugates. The absolute concentration of diene conjugates also remained at the preoperative level after general anesthesia and after heparin administration (200 $\mathrm{IU} / \mathrm{kg}$ ). After the introduction of the extracorporeal circulation, the level suddenly decreased and remained at this lower level throughout the rest of the operation (Fig. 2 , lower panel). However, this decrease was caused by the hemodilution: the correction for hemodilution showed an actual increase in the amount of diene conjugates formed throughout the extracorporeal circulation period (Fig. 2, upper panel). The level of diene conjugate formation was not significantly affected by reperfusion of the heart, but the increase occurred at the introduction of the extracorporeal circulation. The assay for diene conjugates, like the assay for fluorescent chromolipids described previously, is

\section{CORRECTED FOR HEMODILUTION}

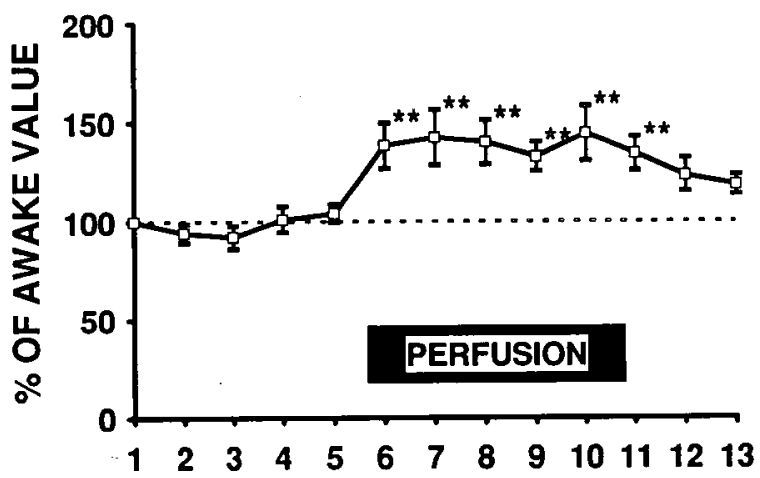

NOT CORRECTED FOR HEMODILUTION

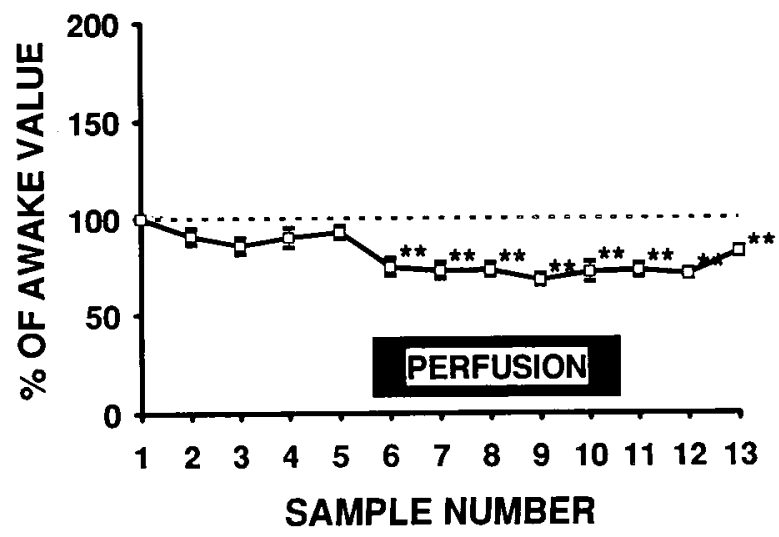

Fig. 2. Line graphs showing the relative amount of diene conjugates in arterial plasma during different phases of CABG operation. Upper panel shows the values after correction for hemodilution; lower panel shows the actual measured plasma concentrations as percentage of first data point (mean \pm SEM of nine patients). Sample time numbers refer to sample times of Fig. 1. ${ }^{* *}$ Two $\times p<0.01$, difference from the first sample by analysis of variance followed by the Newman-Keuls test.

not specific to a single chemical compound but to a group of compounds sharing similar structures. Consequently, the measured values are arbitrary units rather than absolute molar concentrations, and the results are therefore expressed as a percent change from the starting value instead of molar concentrations.

TBA reactive material. Malondialdehyde formation showed, in general, patterns similar to those of diene conjugate formation, but the changes from the preoperative level did not reach significance because of the great variability in the plasma levels (Fig. 3). The starting plasma concentration was $1.8 \pm 0.3 \mu \mathrm{mol} / \mathrm{L}$ (mean \pm standard 


\section{CORRECTED FOR HEMODILUTION}

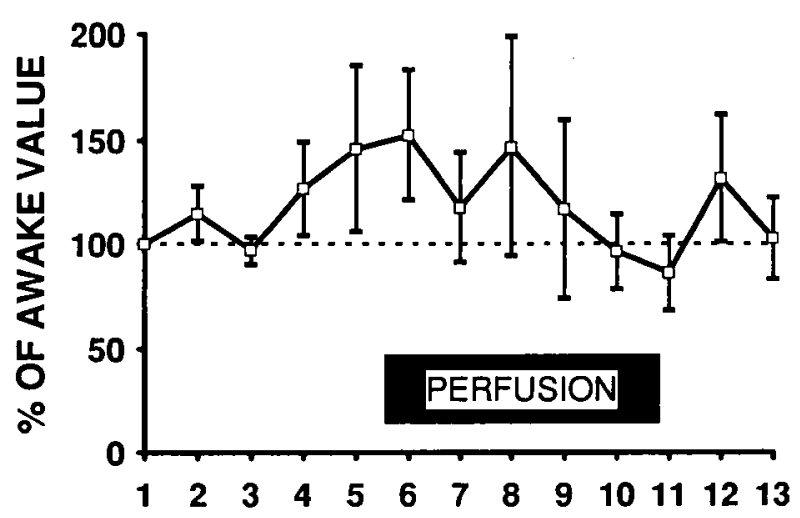

NOT CORRECTED FOR HEMODILUTION

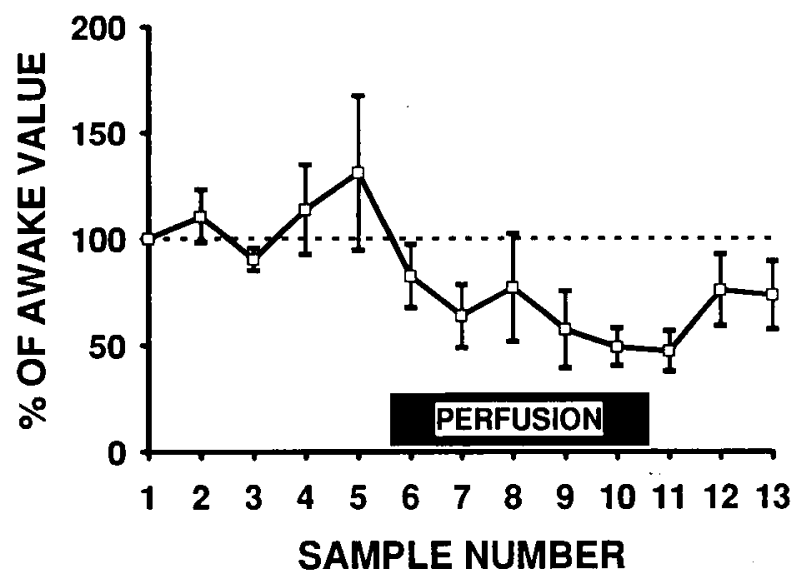

Fig. 3. Line graphs showing relative amount of TBA reactive material (malondialdehyde) in arterial plasma during different phases of CABG operation. Upper panel shows the values after correction for the hemodilution; lower panel shows actual measured plasma concentrations as percentage of first data point (mean \pm SEM of nine patients). Sample time numbers refer to sample times of Fig. 1.

error of the mean [SEM]), and the lowest measured noncorrected plasma concentration was $0.9 \pm 0.2 \mu \mathrm{mol} / \mathrm{L} 5$ minutes after CPB. When the latter value is corrected for the hemodilution, it corresponds to the concentration of $1.6 \pm 0.3 \mu \mathrm{mol} / \mathrm{L}$ in the original starting plasma volume. The values before and after aortic crossclamp removal were both $1.8 \pm 0.4 \mu \mathrm{mol} / \mathrm{L}$, respectively, when corrected to the original plasma volume.

Plasma antioxidant capacity. The ability of plasma to bind free peroxyl radicals formed from azobis(2-amidinopropane)hydrochloride remained essentially intact in spite of the anesthesia or extracorporeal circulation (Fig.
4, lower panel). In fact, when the values are corrected for the hemodilution, the plasma antioxidant capacity actually increased during the time of extracorporeal circulation (Fig. 4, upper panel). The baseline binding capacity was $818 \pm 76 \mu \mathrm{mol} / \mathrm{L}$ (mean $\pm \mathrm{SEM}$ ) and the lowest values were $630 \pm 44$ and $619 \pm 56 \mu \mathrm{mol} / \mathrm{L}$ immediately before and after the aortic crossclamp removal, respectively. When the latter two values are corrected for hemodilution, they correspond to the concentration of $1184 \pm 54$ and $1163 \pm 90 \mu \mathrm{mol} / \mathrm{L}$ in the original plasma volume, respectively. The antioxidant capacity assay became available during the course of this study, and therefore these data include only the last six patients.

\section{Discussion}

The present study was planned to study whether human plasma contains signs of free radical production during CABG operations. This formation is well documented in reperfused animal hearts after the ischemic challenge, but the human heart may react differently because it has low or totally absent superoxide-producing xanthine oxidase activity. ${ }^{2}, 16$ However, it is possible that circulating xanthine oxidase could bind to the coronary walls, and xanthine oxidase is not the only generator of free radicals in vivo. Furthermore, also the nonischemic tissues (e.g., activated neutrophils) are able to generate free radical species. ${ }^{3,6} \mathrm{We}$ wanted to see the maximal free radical formation, and therefore all drugs containing antioxidant properties were avoided, whenever possible. The patients received only their own $\beta$-adrenergic blocking agents, calcium antagonist drugs, and peroral nitrates, and $100 \%$ oxygen was used throughout the operation. Blood samples were collected after every major homeostatic alteration and measured for malondialdehyde (which is a classic but nonspecific free radical reaction product), for diene conjugates (which reflect early phases of free radical reactions), and for fluorescent chromolipids (which are formed with the reaction of aldehydes with membrane phospholipids and reflect late reaction in the free radical cascade). Of these compounds, malondialdehyde is readily excreted in urine, but the appearance of fluorescent chromolipids has not been measured in human urine thus far. Therefore we also collected hourly urine samples for the fluorescent chromolipid analysis. Human plasma is rich in antioxidant compounds that could immediately destroy free radicals when they are formed. Therefore we also measured the ability of plasma samples to trap artificially generated free peroxyl radicals to see whether plasma antioxidants were consumed during the operation.

General anesthesia or heparin administration (200 
$\mathrm{IU} / \mathrm{kg}$ ) did not alter plasma levels of the measured free radical reaction products or plasma antioxidant capacity. The beginning of the extracorporeal circulation caused an immediate increase in the production of all the measured compounds, except plasma malondialdehyde. Fluorescent compounds increased the most, and their plasma concentration remained at the preoperative level in spite of the twofold plasma dilution with $2 \mathrm{~L}$ of crystalloid prime and at least $1 \mathrm{~L}$ of crystalloid cardioplegic solution. These compounds were also readily excreted in urine, but we could not differentiate whether this excretion originated in the plasma or from the kidneys. If the excretion did originate in the plasma, the plasma values underestimate the real rate of their formation.

The plasma level of diene conjugates increased somewhat less than the fluorescent compounds did but had a similar profile. Their plasma concentration decreased slightly, but the increased production is apparent after the correction for the hemodilution. Increased plasma diene conjugate levels during cardiac operations has been reported earlier, but this increase has not been connected to the start of the extracorporeal circulation. Davies and associates ${ }^{4}$ found a small increase in the conversion of linoleic acid to octadeca-9,11-dienoic acid in arterial and mixed venous blood both before and after ischemia during CPB, and it apparently originated in noncardiac tissues. Similar to our findings, those of Hind and associates ${ }^{7}$ included a $20 \%$ to $30 \%$ increase in plasma octadeca-911-dienoic acid that lasted for the time period of extracorporeal circulation. This increase appeared only in plasma free fatty acid fraction, and the authors concluded that it was caused by heparin. Unfortunately, they did not analyze any blood samples after heparin administration but only without extracorporeal circulation.

In our experiments, heparin administration did not increase plasma diene conjugates during the first $5 \mathrm{~min}$ utes, whereas the increase seemed to follow the introduction of the extracorporeal circulation. Of course, we cannot totally exclude the possibility that heparin, later during the perfusion, could have contributed to the increase in the level of diene conjugates in our patients also. Non-heparin-induced release of conjugated dienes was reported by Weisel and associates ${ }^{8}$ who found their release to coronary sinus during the heart reperfusion and after protamine administration. We did not see any additional increase during heart reperfusion or after protamine administration, but we collected the samples from the radial artery, and thus a small amount of diene conjugates formed in the heart could have been diluted in the larger blood volume before the sample collection.

TBA products showed, in general, a similar trend to

\section{CORRECTED FOR HEMODILUTION}

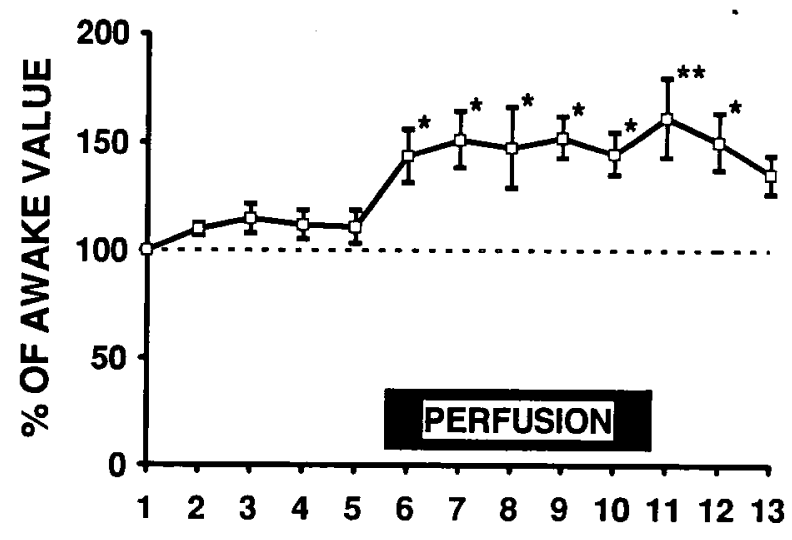

NOT CORRECTED FOR HEMODILUTION

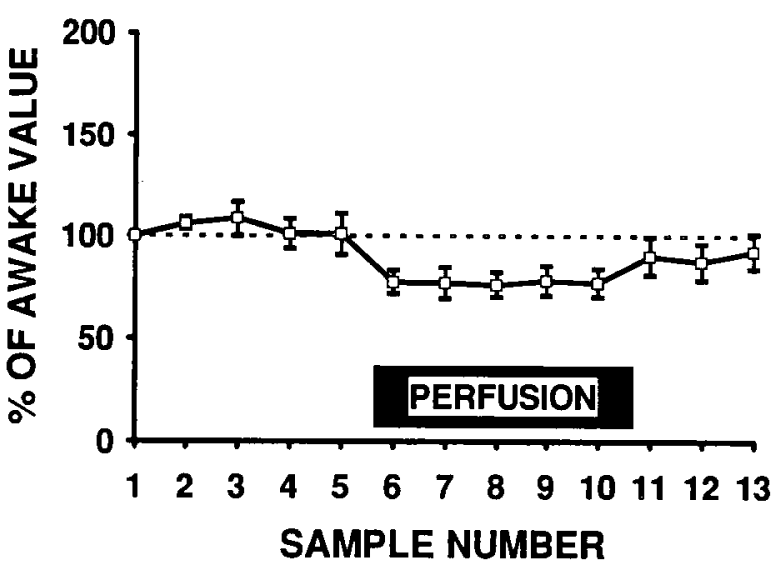

Fig. 4. Line graphs showing relative peroxyl radical binding capacity of arterial plasma during different phases of CABG operation. Upper panel shows the values after correction for the hemodilution; lower panel shows actual measured plasma concentrations as percentage of first data point (mean \pm SEM of six patients). Sample time numbers refer to sample times of Fig. 1. ${ }^{*}$ Two $\times p<0.05 ; * * 2 \times p<0.01$; difference from the first sample by analysis of variance followed by the Newman-Keuls test.

that of the diene conjugates, but the plasma concentrations varied greatly, and no statistically significant changes occurred during the operation. Earlier reports on plasma malondialdehyde have also shown variable results. Rashid and William-Olsson ${ }^{22}$ detected a continuously increasing malondialdehyde concentration that correlated with the leukocyte count in a clinical setup similar to that of our present work. Prasad and associates ${ }^{6}$ found slightly increased malondialdehyde levels before aortic crossclamping and 24 hours after the operation but not 
after closing of the chest. Royston and associates ${ }^{3}$ reported increased malondialdehyde activity 15 to 25 minutes after crossclamp removal, whereas earlier during the perfusion TBA reactivity remained constant. Davies and associates ${ }^{4}$ detected an increase at 2 to 10 minutes of reperfusion in arterial and mixed venous blood but not in the blood from the coronary sinus. Because TBA reaction shows great variability, is nonspecific for free radical generation, and could be affected by several factors, we believe that it is not ideal for the estimation of free radical reactions in vivo.

Originally, we hypothesized that antioxidants would be consumed during the operation, and it was unexpected that plasma ability to bind free peroxyl radical species would actually increase during the extracorporeal circulation. The reason for this increase remains unresolved, but it could be caused by, for example, rapid induction of antioxidant enzymes or by liberation of intracellular antioxidant compounds either by excretion or through cellular breakdown. Although plasma free radical trapping capacity did not decrease, it is possible that antioxidants could be consumed at the site of free radical formation. This possibility is supported by the finding that myocardial $\alpha$-tocopherol concentration was decreased after reperfusion. ${ }^{8}$

The total plasma content of the free radical reaction products was estimated by correcting the measured plasma concentration by a plasma dilution factor. We used packed red cell volume as an intravascular nondiffusible indicator. We believe that it is a reliable factor in our surgical setup, where all the bleeding was returned continuously to the perfusion circuit and no packed red cells were added. Some error is caused by the small amount of red cells escaping the suctions, and the swelling of the cells could have the opposite effect. These errors are small in comparison to the hemodilution effect caused by the addition of at least $3 \mathrm{~L}$ of crystalloid fluid that approximately doubled the plasma volume. Furthermore, only diene conjugates showed some dilution effect, whereas the noncorrected plasma concentration of the other compounds remained unchanged. Therefore, it is evident that their production increased during the extracorporeal circulation, although the exact amount of this increase may be difficult to calculate.

Our results show that free radical reaction products appear in arterial plasma at the beginning of the extracorporeal circulation before any ischemic challenge. No further increase was detected after reperfusion of the ischemic heart. The increase was biggest in the levels of fluorescent chromolipids, followed by conjugated dienes, whereas malondialdehyde concentration did not show significant changes. Furthermore, fluorescent chromolip- ids appeared readily in urine. It is possible that different exposures could favor different free radical reactions, and the compounds measured should be selected accordingly. Our results do not exclude the possibility that free radicals are formed in the postischemic cardiac tissue during reperfusion, but they suggest that arterial blood samples are not appropriate when cardiac reactions are studied. Instead, more localized blood samples from the coronary sinus, for example, should be used for that purpose. The clinical significance of increased plasma free radical trapping activity remains unknown. The results suggest that no shortage of plasma antioxidants developed, but the appearance of free radical reaction products in plasma shows that antioxidants did not totally prevent free radical reactions. However, it is possible that plasma antioxidants may help in preventing the formation of chain reactions, as well as remote damage caused by circulating free radicals. Further studies are needed to identify the site, time, and type of free radical reactions during the cardiac operation before relevant treatment for their prevention can take place.

We gratefully acknowledge the skillful technical assistance of Leena Söderholm and Raija Söderholm.

\section{REFERENCES}

1. Cross CE, Halliwell B, Borish ET, et al. Davis Conference: oxygen radicals and human disease. Ann Int Med 1987; 107:526-45.

2. Kloner RA, Przyklenk K, Whittaker P. Deleterious effects of oxygen radicals in ischemia/reperfusion. Circulation 1989;80:1115-27.

3. Royston D, Fleming JS, Desai JB, Westaby S, Taylor KM. Increased production of peroxidation products associated with cardiac operations. J THORAC CARDIovasC SuRG 1986;91:759-66.

4. Davies SW, Underwood SM, Wickens DG, Feneck RO, Dormandy TL, Walesby RK. Systemic pattern of free radical generation during coronary bypass surgery. Br Heart J 1990;64:236-40.

5. Menasché $P$, Antebi $H$, Alcindor L-G, et al. Iron chelation by deferoxamine inhibits lipid peroxidation during cardiopulmonary bypass in humans. Circulation 1990;82(Suppl):IV390-6.

6. Prasad K, Kalra J, Bharadwaj B, Chaudhary AK. Increased oxygen free radical activity in patients on cardiopulmonary bypass undergoing aortocoronary bypass surgery. Am Heart J 1992;123:37-45.

7. Hind CRK, Griffin JF, Pack S, et al. Effect of cardiopulmonary bypass on circulating concentrations of leucocyte elastase and free radical activity. Cardiovasc Res 1988; 22:37-41.

8. Weisel RD, Mickle DAG, Finkle CD, et al. Myocardial free-radical injury after cardioplegia. Circulation 1989; 80(Suppl):III14-8. 
distribution and physiology. Acta Physiol Scand 1986; 548(Suppl):87-99.

17. Esterbauer H, Koller E, Slee RG, Koster JF. Possible involvement of the lipid peroxidation product 4-hydroxynonenal in the formation of fluorescent chromolipids. Biochem J 1986;239:405-9.

18. Corongiu F, Lai M, Milia A. Carbon tetrachloride, bromotrichloromethane and ethanol acute intoxication. Biochem J 1983;212:625-31.

19. Bird RP, Draper HH. Comparative studies on different methods of malonaldehyde determination. Methods Enzymol 1984;105:299-305.

20. Wayner DDM, Burton GW, Ingold KU, Locke S. Quantitative measurement of the total, peroxyl radical-trapping antioxidant capability of human blood plasma by controlled peroxidation. FEBS Lett 1985;187:33-7.

21. Alanko J, Riutta A, Mucha I, Vapaatalo H, Metsä-Ketelä T. Modulation of arachidonic acid metabolism by phenols: relation to positions of hydroxyl groups and peroxyl radical scavenging properties. Free Rad Biol Med 1993;14:1925.

22. Rashid MA, William-Olsson G. Are leukocytosis and lipid peroxidation involved in ischemic or reperfusion injury in cardiac surgery? Thorac Cardiovasc Surg 1991;39: 193-5.

16. Parks DA, Granger DN. Xanthine oxidase: biochemistry, 